\title{
Analyzing the Factors Influencing Farmers' Willingness to Produce Safe Agricultural Products: Evidence from Vegetable and Rice Farmers in Sri Lanka
}

\author{
Dhammika. P. Withanage \\ dwithanage@sjp.ac.lk
}

\begin{abstract}
Organic farming has been widely recognized as the best alternative that provides healthy food, environmental protection and ecological balance which have been seriously threatened by high input agricultural methods. This demands the need of promoting safe food production which has been considerably neglected especially in the developing countries. The aim of this article was to investigate the factors affecting to farmers' willingness to produce safe agricultural products or to adopt organic farming methods. On the basis of field survey data obtained from rice and vegetable farmers in Uva province in Sri Lanka and utilizing a binary logistic model this study found that farmers' willingness is positively influenced by a number of factors: farmer's education level, household income, income from agricultural activities, years of farming, land extent, relative price of organic products, knowledge on eco system services, risk behaviour, and entrepreneurial skills. Finding suggest that farmers could be motivated to produce safe food products by incorporating these influential variables in targeted programs rather than giving ad hoc economic incentives.
\end{abstract}

Key words: Safe agricultural products; Farmers’ willingness; Organic farming; Sri Lanka

DOI: $10.7176 / \mathrm{JESD} / 10-2-19$

\section{Introduction}

Organic farming has been defined as a natural and sustainable farm management practice, which depends upon managing the agro-ecosystem instead of relying on chemicals, such as pesticides, artificial fertilizers, additives, and genetically modified organisms (Britanica, 2018). It is a sustainable farming method which uses techniques like crop rotation, vermi-composting, bio-fertilizers, crop management, animal manure, off-farm organic waste, crop residues etc., which helps soil to stay alive, healthy and food to be safe. Food safety is basically enhanced by the organic farming specifically because of three factors: lower nitrogen application; avoidance of pesticide use; no use of chemical fertilizers. The high input agriculture has created immense health problems such as cancer, diabetes and cardiovascular diseases (WHO, 1990; Minif et al., 2013; García, 2003). Favorable effects of organic farming methods minimize the incidence of cancer and the transfer of resistance genes from animal production systems to human pathogens (Hansen et al., 2002; Gupta, 2017). Therefore, increasing health conscientious by consumers has led to an increase in demand for the pollutant free healthy and safe food products like organic foods. This growing trend towards the safe agricultural products offers scope for farmers to produce safe foods for the markets worldwide while the organic farmers are said to be true life-savers who work hard to grow healthy and nutritious crops (May \& Paratori, 2012).

Though the organic farming, by the word, is relatively new to Sri Lanka, traditional agriculture in the country is environmentally friendly, culturally sensitive, and sustainable management system. Researchers have stressed that Sri Lanka as a country with full of natural resources has a large potential to fulfil a significant portion of ever-growing market demand for organic products in the World. Processing organic agro products in the plantation sector such as tea, spices, cashew and coconut products has reported a rapid progress (Gunasena, 2008; Rambukwella \& Priyankara, 2016) yet the non-plantation sector's growth is lagging behind. Especially, vegetable cultivation is one of the most important sectors in agriculture. Diverse agro-ecological regions in the country are well suited for the cultivation of different kinds of vegetable crops. Moreover, it is considered as an important component in the daily diet of people of Sri Lanka and so that, there is a constant demand for vegetables in local market. At present, national vegetable production meets nearly $60 \%$ of the vegetable requirement (Dharmasena et al, 2017). This sector provides main life supplies of the people in the country. Hence the quality and safety of these products affect the people's life closely (May \& Paratori, 2012; McCluskey, 2000). Widespread of non-organic rice and vegetable production has been identified as the prime reason for the polluted environment which filled with toxic and hazardous chemicals. This hidden environment cost may be the prime cause for recent weakening of the human immune system leading to a significant increase of allergies, incidence of ailments such as catarrh, cancer, kidney disease etc (Axel et al., 2017; Bradbury, 2014). Therefore, increasing the production and consumption of organic foods may reduce the health risk and thereby the enormous public health expenditure burden giving a healthy labor force to the country. Further, it is claimed that the widespread adoption of organic farming methods could result in rural revitalization, regional self-sufficiency 
in food production and changes in the existing "capital-intensive structure of agriculture" (Batie and Taylor, 1989). Consequently, both developed and developing countries have increasing taken efforts to promote and develop organic farming. As a result, the total area of organic farmland has reported to be increased from 11 million hectares in 1999 to 50.9 million hectares in 2017 worldwide (Willer and Lernoud, 2017).

It is well acknowledged the need of converting existing farming practices into organic farming. However, Sri Lanka is still very backward in the organic sector. Therefore, it is stressed the need of encouraging the core of the agricultural sector, farmers, to move into organic farming. This demands a comprehensive investigation of triggering as well as constraint factors at farmer level where there is a dearth of academic contributions. Further, the main concern regarding the lagging motivation towards the production of healthy and safe agricultural products in the country is the insufficient governments' regulations and incentives. However, scholars have shown that the three exist a huge knowledge gap and thereby information asymmetry between producers, consumers and authorities. Since the theoretical foundation as well as the concepts have not been well defined, producers are not sure of whether they have used appropriate methods to guarantee food quality, and consumers are also uncertain whether they receive quality products (McCluskey, 2000; Ranaweera, 2016). When addressing this informational asymmetry, it is essential in understanding the farmers' motivations and their willingness of adopting self-sustaining agricultural production system (May and Paratori, 2012) which may "lead to developing a stable and balanced ecosystem, encouraging all natural cycles, protecting soil, water, animals, plants and human health, which would in turn result in creating a stable and economically viable production system in the long term (Ranaweera, 2016). Hence, the main objective of this paper is to investigate the economic and noneconomic determinants of farmers' motivations and their willingness to produce safe agricultural products.

\section{Literature review}

According to the previous empirical analyses, factors that affect farmers' willingness to produce quality agricultural products mainly include the individual characteristics such as the farmer's gender, age, level of education, risk preferences, ability to perceive chemical pesticide residue hazards, price of organic products, relative price, satisfaction about the price of organic products, expected income, production area or land extent, types of land ownership, farm machinery, planting experience, participate in the training of agricultural products' quality and safety; experience of receiving relevant training, signing of agricultural product purchases and sale contracts (sales methods), information and instructions access, status of government supervision and regulations, production scale, government subsidy, guidance from agricultural technicians and joining agricultural industrialization organizations (Burton et al. 1999; Ceylan et al. 2010; Dai Yunyun and Wang Kai, 2008; Läpple and van Rensburg 2011, Genius et al. 2006; Xie, et al.,2015; Ying and Min, 2011; Zhang, 2008; Zhu et al., 2014).

Ying and Min (2011) found that farmers' decision on producing safe agricultural products positively influenced by the relative price of safe agricultural products, production scale, government subsidy, guidance from agricultural technicians and joining agricultural industrialization organizations. According to them farmers' age and family income have significant negative effects on the decision while the most influential positive impact was given by the production scale, relative price of safe agricultural products and joining of agricultural organizations. Similarly, Burton et al. (1999), Läpple and Van Rensburg (2011) found significant negative impact of age on the adoption of organic production. In contrast, Chen et al. (2009), Wang (2012) and also Xie, et al., (2015) claimed that age as a positively impacted variable.

As Xie, et al., (2015) found, risk preference and abundant family labor and expected income have strong positive impact on producing organic foods. Farmers who are risk lovers, have sufficient family labor and expect a high income have shown a strong motivation towards safe farming. However, for Dai Yunyun and Wang Kai (2008 as in Ying and Min, 2011) farmers' educational background, family labor and agricultural income proportion and family income were not significant in predicting organic farming decision. Further, Xie, et al., (2015) posited that the farmers who are well aware of the environmental benefits of organic farming showed a strong willingness to switch to it.

The above discussion clearly shows that different researchers in different contextual backgrounds have found different results regarding the farmers' willingness of producing safe agricultural products. It implies that the phenomenon interested is sensitive to the economy or sometimes for the regional specific factors, living standards and also attitudes.

\section{Materials and methods}

Research design: Since the current study seeks to investigate and quantify the causal and effect factors of safe food products, primarily this an explanatory research which adopt both descriptive and correlational types as well. Basically the study was designed under non experimental manner.

Sampling and data collection: Sampling for the main questionnaire survey was done under multi stage cluster sampling method. First two divisional secretariats from each administrative district, Badulla and Monaragala, 
were randomly selected and then four Grama Niladari (GN) divisions from each DS were selected. Selected GN divisions from Badulla district were Bogahakumbura, Kandakatiya, Baddekumbura and Bandarawela-East while Wellawaya, Kiriibbanwewa, Buduruwagala, Sewanagala were selected from Monaragala district. Then a random sample of farmers were selected from a randomly chosen village from each GN. Altogether a sample of 1070 subjects from both districts was selected and the questionnaire was administered. Effective sample size for the analysis was 890. The contents of the questionnaire was as follows: a. general characteristics of rural households, including age, race, region etc, educational status of householder, the number of family members the details; b. Dwelling characteristics, assets endowment, monthly household expenditure and income, etc.; c. data on production of vegetables/rice including planting varieties, fertilizer/pesticide use, farming and harvesting practices, marketing, farm loan history, and agricultural insurance experience, etc.; d. information about awareness of organic farming, including knowledge about the organic production technologies, farmers' price expectations; e. awareness related to ecosystem services

Empirical model: The dependent variables for the current study is farmer's willingness to produce safe agricultural products. Therefore the outcome variable was dichotomous assigning 1 to represent "willingness" and 0 otherwise. Binomial logistic regression is the form regression that can be used when the dependent is dichotomy and the independents are of any type: continuous, categorical. Logistic regression can be used to predict the binary outcome variable on the basis of independents, to determine the variation of the dependent variable that is explained by the independents as well as to identify the relative importance of individual predictors. Hence, the use of logistic regression was appealing for the current study. In this regard, the logistic regression model consisting of $\mathrm{n}$ independent variables can be described as:

$\operatorname{logit}(P)=\beta_{0}+\beta_{1} X_{1}+\beta_{2} X_{2}+\cdots+\beta_{n} X_{n}$

This shows the application of maximum likelihood estimation after transforming the dependent variable into logit variable: natural log of the odds of the dependent occurring or not. The left side of the equation denotes the natural logarithm of likelihood which corresponds to the ratio of the occurrence and non-occurrence of events. Hence,

$\operatorname{logit}(P)=\ln \left(\frac{P\left(Y_{1}\right)}{P\left(Y_{0}\right)}\right)=\beta_{0}+\beta_{1} X_{1}+\beta_{2} X_{2}+\cdots+\beta_{n} X_{n}$

Where $Y_{1}$ means the farmer is willing to engage in organic production, $Y_{0}$ otherwise or the farmer is not willing to produce safe food. The left side of the equation denotes the natural logarithm of likelihood which corresponds to the ratio of the occurrence and non-occurrence of events. The independent variables $X_{1}$ to $X_{n}$ represent independent variables or the factors affecting the farmers' willingness to produce safe agro products.

Variables: Dependent variable: Farmers' production willingness of safe agricultural products is binary variable which is assigned a value 1 if farmers' being willing to produce safe agricultural products and 0 otherwise.

Independent variables:

Age (HHage): in years

Education (HHedu): Years of schooling

Income: (Incm): Categorical variable was derived for monthly expenditure (income proxy) deciles and used as ordered variable to avoid collinearity

Years of farming: Farming experience in years

Agri income (Agri_inc): Income received from last harvesting was categorized in to three categories as Rs. 25000 or less, $25000-50000$ and above 50000 and two dummy variables were constructed

Land extent (Land_Acres): considering the sample characteristics, a dummy variable was constructed; $1=1$ ess than one acres; 0 otherwise

Farmers Perception on relative price (Relative_price): Ordered variable having options: $1=$ No difference; $2=$ two times higher; $3=$ three times higher; $4=$ more than three times higher

Knowledge of ecosystem services and benefits (Eco_Knw: Likert scale data for six items that are related to ecosystem services were collected initially. Secondly a composite variable was constructed using principle component method. Score of the un-rotated first component which extracts 56 percent of the total variation was saved and use as the measure of farmer's knowledge. (KMO $=0767$ and item loadings exceeds 0.6). Then the binary variable for the analysis was constructed assigning value 1 for above mean and 0 otherwise.

Risk behaviour (Risk_take): This is initially a composite score derived using PCM. Four items related to risk behaviour were iterated and first component was used to create binary variable for the analysis. (Value 1 for the subjects lie above mean and 0 otherwise)

Farmer's entrepreneurship skill (Entre_skill): Entrepreneurship skill was measured using four items related to entrepreneurial self-efficacy: new markets. New marketing strategies, record keeping and locus of control. 
Derived score was used to create the dummy variable for the analysis assigning value 1 for the subjects lie above mean and 0 otherwise.

\section{Results}

Table 1. Age and education level of farmers

\begin{tabular}{lcclcc}
\hline Age & Head $\%$ & Spouse $\%$ & \multicolumn{1}{c}{ Edu level } & Head $\%$ & Spouse $\%$ \\
\hline $18-29$ & 0.1 & 1.7 & Primary or less & 10.3 & 3.5 \\
$30-39$ & 14.8 & 12.9 & Grade 6-10 & 52.1 & 35.6 \\
$40-49$ & 23.6 & 24.6 & O/L & 23.2 & 21.6 \\
$50-59$ & 40.7 & 35.7 & A/L & 4.2 & 14.3 \\
$60-69$ & 14.6 & 7.4 & Above A/L & 5.3 & 2.0 \\
$70+$ & 2.2 & 1.1 & Mean & 9.4 & 10.3 \\
Mean & 51.05 & 48.9 & & & \\
Min & 29 & 27 & & & \\
Max & 81 & 72 & & & \\
\hline
\end{tabular}

Source: Author's calculations based on sample survey

Once the basic demography of the sample is taken, it was recoded that 98 percent of the respondents were male while only 2 percent of them were female. According to the data reported in Table 1 , approximately $2 / 3$ of farmers are $40-60$ age groups while a negligible proportion, 0.1 percent, is between of 18 to 29 years. Sample mean is recorded as 51 years. Once the education level is concerned, as shown in the Table 1, there is no illiterate farmers are presented in the sample while more than half of the sampled farmers have at least junior secondary level education. Though the GCE Advance level educators are less, more than one fifth of the farmers have completed Ordinary level. Spouses' education data follows the same pattern as shown in the last column of the Table 1. As shown in Figure 1, Buddhist are the majority and 11.3 percent of the sampled farmers are Muslims. Once the marital status in concerned, the majority are married.

Figure 1: Religion and marital status of farmers

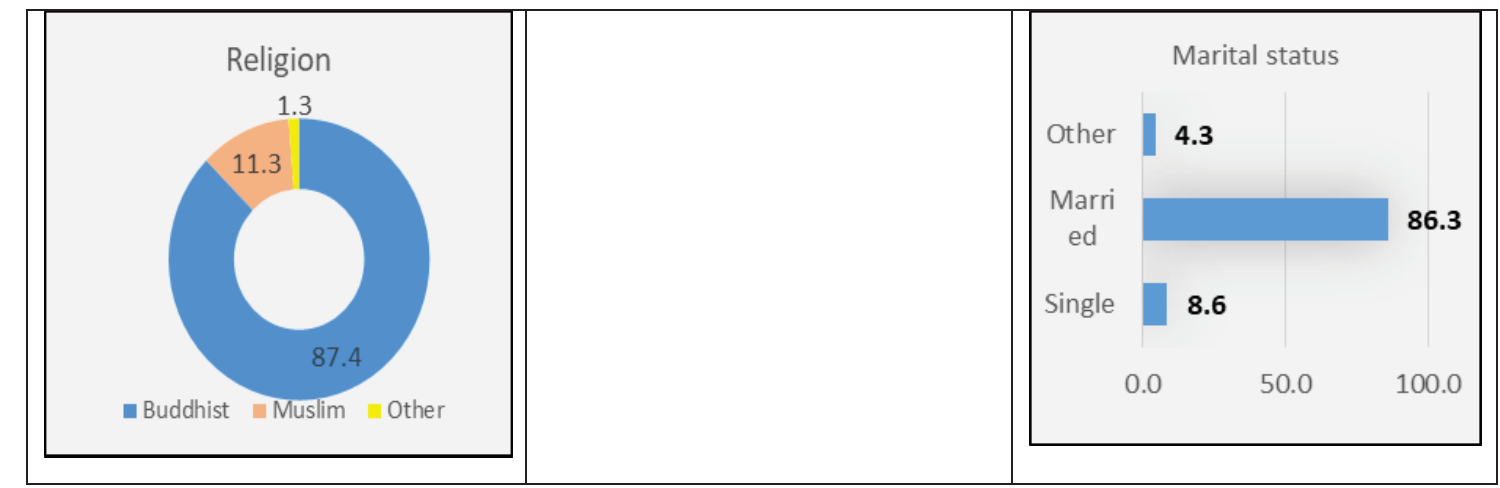

Source: Author's calculations based on sample survey

Reported household expenditure as a proxy for their income, basic facilities and assets situation of the sampled population are considered as in Table 2. Revealed data shows that monthly expenditure varies from Rs. 8000 to 60000 for the sample while the majority in the sample spent around Rs. 35000 per month. Average monthly expenditure of a farmer household is Rs. 23985 with a standard deviation of 10555 . When the expenditure distribution is considered, it is shown that 11 percent of the farmers spend less than 10000 rupees a month while a little less than 30percent of them are in between Rs. 10000 and 20000. For the majority, monthly expenditure lies between Rs. 30000 and 40000. The percentage of farmers who spend more than 50000 for their day today household needs is 3.4 . 
Journal of Economics and Sustainable Development ISSN 2222-1700 (Paper) ISSN 2222-2855 (Online)

Vol.10, No.2, 2019

DOI: $10.7176 /$ JESD

Table 2: Household expenditure, basic infrastructure and assets endowment of the sample

\begin{tabular}{|c|c|c|c|c|c|c|c|c|}
\hline $\begin{array}{l}\text { Expenditure } \\
\text { LKR }\end{array}$ & $\%$ & Item & Source & $\%$ & Goods & $\%$ & Vehicle & $\%$ \\
\hline $10000-$ & 11.2 & Cooking & Gas & 9.6 & Fridge & 30.2 & Bicycle & 26.7 \\
\hline $10000-20000$ & 29.2 & & Firewood & 89.9 & TV & 100 & Motorbike & 12.2 \\
\hline $20000-30000$ & 36.1 & & Well & 64.4 & DVD/VCD & 17.1 & $\begin{array}{l}\text { Three } \\
\text { Wheel }\end{array}$ & 4.8 \\
\hline $30000-40000$ & 13.9 & & Pipe & 29.8 & Blender & 49.2 & Car & 0.1 \\
\hline $40000-50000$ & 3.3 & Water & Other & 6.1 & Rice cooker & 52.3 & Van & 0.01 \\
\hline $50000-60000$ & 2.1 & Lightning & Electricity & 99.9 & Sew M & 41.2 & No vehicle & 56.1 \\
\hline $60000-70000$ & 0.7 & House & Own & 83.3 & Phone & 2.5 & & \\
\hline \multirow[t]{4}{*}{$70000+$} & 0.6 & & Parents & 16.5 & Wash M & 1.8 & & \\
\hline & & Road & Path & 14.1 & Gas C & 33.2 & & \\
\hline & & & 3 wheel & 41.3 & Oven & 6.5 & & \\
\hline & & & 4 wheel & 44.6 & & & & \\
\hline
\end{tabular}

Source: Author's calculations based on sample survey

Once the basic lifestyle conditions are taken, majority of them utilize biomass for cooking while 83 percent of them have their own houses. More than 85 percent of the premises have at least three wheeler road access, however there is no own vehicle for the majority.

Table 3: Farming years and land characteristics

\begin{tabular}{cccclc}
\hline $\begin{array}{c}\text { Years of } \\
\text { farming }\end{array}$ & $\%$ & $\begin{array}{c}\text { Land extent } \\
\text { Acers }\end{array}$ & $\%$ & $\begin{array}{c}\text { Land } \\
\text { ownership }\end{array}$ & $\%$ \\
\hline $0-5$ & 1.9 & $1-$ & 32.1 & Inherent & 67.8 \\
$5-10$ & 12.3 & 1 & 35.9 & Other & 32.3 \\
$11-14$ & 5.3 & 2 & 10.3 & & \\
15 & 15.8 & $2+$ & 8.9 & Farming & \\
16 & 5.6 & & & By tradition & 74 \\
17 & 2.6 & & & Other & 26 \\
18 & 8.8 & & & & \\
$20+$ & 43.1 & & & & \\
\hline
\end{tabular}

Source: Author's calculations based on sample survey

When farming related characteristics are considered as in Table 3, the majority of the farmers have been farming more than a decade. A considerable proportion of the sample have more than two decades of experience. Average land extent owned by the farmers in the sample is 1.6 while the mode extent is 2 . As shown in Table 3 , almost one third of the farmers possess less than one acres. Percentage of the farmers who are producing in their inherited land is 67.8 and 74 percent is famers by decent. 
Figure 2: Organic farming: Willingness of and actual practice

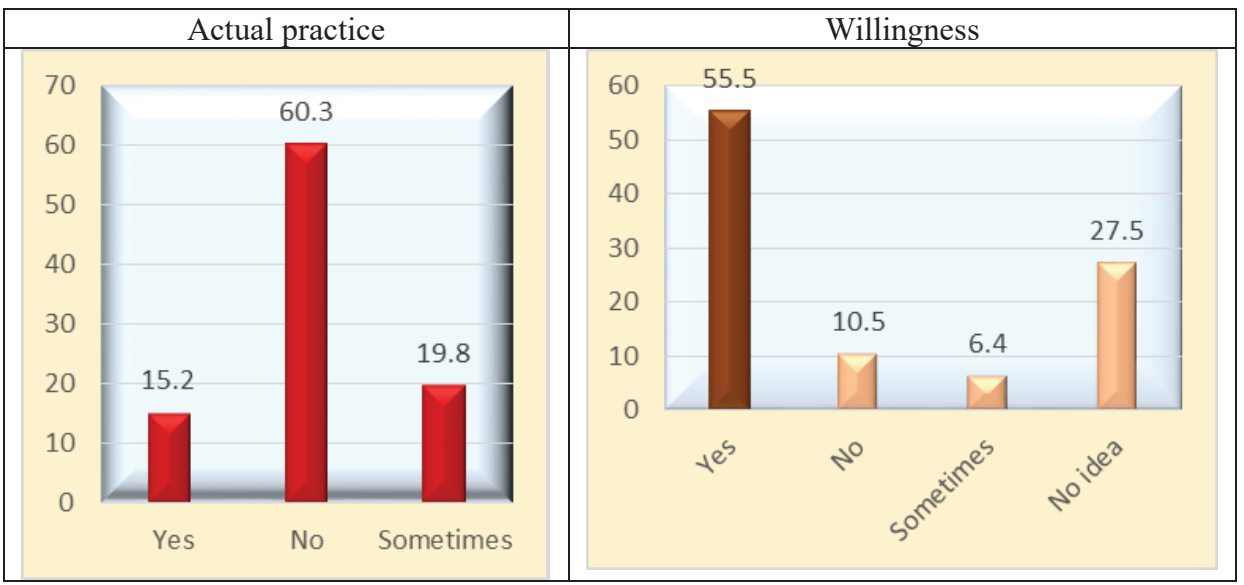

Source: Author's calculations based on sample survey

As illustrated in Figure 2, farmers who utilize environment friendly inputs is 15 percent while the farmers who are willing to practice organic farming is more than 55 percent. This number would be expanded to 90 percent if "sometimes" and "no idea" groups are added.

Table 4: Mean values of main covariates

\begin{tabular}{lrr}
\hline \multirow{2}{*}{ Variable } & \multicolumn{2}{c}{ Willingness : Safe agri* } \\
\cline { 2 - 3 } & \multicolumn{2}{c}{ Yes } \\
\hline HHage & 55.12 & 51.80 \\
HHedu & 10.00 & 9.70 \\
Incm & 29531.00 & 21408.00 \\
Agri_inc & 65718.00 & 59078.00 \\
Land_Acres & 1.25 & 1.90 \\
Relative_price & 2.43 & 1.00 \\
Eco_Knw & 0.28 & -1.70 \\
Risk_take & 0.72 & 0.13 \\
Entre_skill & 0.93 & 0.23 \\
\hline SoutAw
\end{tabular}

Source: Author's calculations based on sample survey

Uncontrolled results are reported in Table 4. Accordingly, the mean values of the main covariates seemed to have expected impacts on the dependent variable. Mean age and also the years of education of household head or respondent is slightly higher for intended group (willing). Household income of the farmers those who are willing to do safe agro products is about 37 percent greater than that of unwilling group. When it comes to the income from agricultural products, farmers in safe agro production group earned above 65000 rupees while it lies below 60000 for the other group. Land size of the intended group is smaller while the relative price is much higher for them. Once risk taking and the knowledge are concerned, mean values of both variables are grater for safe producers. Compare to the farmers who dislike to adopt organic farming strategies, entrepreneurship skills are greater for those who like to adopt such farming methods. 
Table 5: Logistic regression results on farmer's willingness

\begin{tabular}{lcccc}
\hline Variables & $\beta$ & S.E. & Sig. & $\operatorname{Exp}(\beta)$ \\
\hline Farmer's age & 0.014 & 0.01 & $\mathrm{~ns}$ & 1.01 \\
Farmer's education (Yrs) & 0.11 & 0.01 & $*$ & 1.01 \\
Spouse's education (Yrs) & -0.93 & 0.06 & $\mathrm{~ns}$ & 0.91 \\
Household income & 0.611 & 0.09 & $* * *$ & 1.84 \\
Agricultural income (D1: 25-) & 2.13 & 0.42 & $* * *$ & 8.47 \\
Agricultural income (D2: 35+) & 1.41 & 0.26 & $* * *$ & 4.11 \\
Years of farming & 0.043 & 0.01 & $* *$ & 1.04 \\
Land extent & 0.43 & 0.17 & $* *$ & 1.54 \\
Relative price & 0.405 & 0.10 & $* * *$ & 1.49 \\
Knowledge of ecosystem services & 1.13 & 0.21 & $* * *$ & 3.10 \\
Risk behaviour & 2.84 & 0.45 & $* * *$ & 17.75 \\
Farmer's entrepreneurship skill & 1.74 & 0.32 & $* * *$ & 5.73 \\
\hline
\end{tabular}

$$
* * * \mathrm{p}<0.001 ; * * \mathrm{p}<0.01 ; * \mathrm{p}<0.05
$$

Table 5 presents the results of the logistic model, where the dependent variable takes 1 when a farmer is willing to produce safe agro product and 0 otherwise. The coefficients reported in first column are the marginal effects that have been derived controlling for other effects. Overall model fit indices were good: the model $\chi^{2}$ value $141.9 ; \mathrm{p}<.001$, pseudo $\mathrm{R}$ square values are reasonably good and comparable recording Cox \& Snell as 0.206 and 0.292 for Nagelkerke. The $\chi 2$ value of 126.1 is insignificant at 5 percent level of significance in HosmerLemeshow test proving that the model fits to the data well.

Results reported in in Table 5 indicated that all the independent variables except farmer's age and spouse's education are significant at conventional levels. Farmer's education level is positively significant 5 percent level of significance. $\beta=0.11, \mathrm{p}<0.05$. A year change in education will increase odds for being in the safe producers group by 1.01 times. Household nominal income is positively significant at one percent level of significance. Unit change in income leads to increase odds of been choosing safe agro production by almost 2 . Beta coefficient for both lower and higher agricultural income earners are positively significant in predicting safe agri choice at one percent level of significance reporting beta values 2.13 and 1.41 respectively. Farming experience exhibits positive influence at one percent significance level. Land extent is positively significant in explaining safe agri choice. As depicted in Table 5, farmers who own one acres or less are more likely to choose organic farming while farmer's perception on the prices of organic products are strongly, positively significant at one percent level of significance. Results further indicated that farmer's willingness of producing safe products is positively strongly predicted by their knowledge about eco system services, risk behaviour and also entrepreneurship skills: $\beta=1.13, \mathrm{p}<0.001 ; \beta=2.84, \mathrm{p}<0.001 ; \beta=1.74, \mathrm{p}<0.001$.

\section{Discussion}

According to the results reported in the proceeding sections, most of the demographic factors like age, gender, marital status are not influential in choosing organic farming. Some research findings regarding age reveals that farmers are more likely to conduct organic farming when they get elder (Xie et al., 2015) while for some it is negative (Ying and Min, 2011). The different conclusion made by this study may be due to the characteristics of the sampled population. Significance of education implies when the educational background of farmers is higher, their production willingness of safe products are also higher. It was found that one of the important factors for choosing organic farming is household income. The higher the level of income, the higher the motivation towards safe agricultural production. Since the contribution of other income to total household income is high for higher income families, they have enough economic freedom to test new production strategies. Therefore, increased total household income is a triggering factor. 
Data revealed that the income earned from farming is positively associated with safe production choice for the low and high ends but not for the middle. It means that when agricultural income is low and it is not sufficient, there would be a strong need to increase it sufficiently. Therefore, compared to middle income receivers low income earners are more likely to transit into organic farming. Farmers who receive fairly good income from agricultural activities also have strong willingness to improve existing production method.

As expected more experienced farmers are more willing to turn to organic production. Experienced farmers are well aware of the hazards of the existing system and appreciate the values as well as health benefits of conventional methods. Therefore, as evidence from focus group discussions, experience farmers, are more willing to take the step towards the contemporary need and are enthusiastic in producing healthy foods.

It was found that the scale of the production is sensitive in promoting farmer's willingness. Farmers who have small lands tend to transit into healthy production. Compared to the families that owned large lands, small land holders may have less production capacity and thereby low income. They will be benefited by increasing the productivity of their small lands and joining with a growing market. Farmers believe that smallness of the land gives the technical feasibility to apply newly improved organic methods. For instance, they revealed that it is somewhat easy to do pest controlling in constructed tunnels.

Perceived relative price of safe products exhibits positive influence implying that the higher price of organic products the higher the profit expected and farmers are more willing to turn to organic production. This implies that the profit is the important drive of farmers' production willingness of safe agricultural products. For a considerable percentage, "there is no price difference" or "no idea". This means that there is a grate information asymmetry even among the farmers. Market information does not reach to the producers sufficiently.

Knowledge about eco system services demonstrated a strong influence in preferring to produce safe agricultural products. Farmers who are well aware of the health benefits of healthy environment and safe agricultural products are more willing to adopt organic methods. Knowledge on ecosystem services and its benefits on human life seems to be helped in changing the attitudes towards producing non poisoned products. Farmers are aware of health hazards and especially chronic kidney diseases valued fair production methods. Most of them do not viewed farming as a means of obtaining income. As expected risk preference and also entrepreneurship skill level showed positive influence. The higher the farmers risk preference and entrepreneurial spirit the higher the preference to adopt new methods.

\section{Conclusion}

The aim of this article was to investigate the factors affecting to farmers' willingness to produce safe agricultural products or to adopt organic farming methods. On the basis of field survey data obtained from rice and vegetable farmers in Uva province and utilizing a binary logistic model this study found that farmers' willingness is positively influenced by a number of factors: farmer's education level, household income, income from agricultural activities, years of farming, land extent, relative price of organic products, knowledge on eco system services, risk behaviour, and entrepreneurial skills while most of the demographic factors like age is not influential.

Results revealed that experienced farmers are more willing to produce organic products, provided that they have been given an effective support. Thus designing of an effective incentive system will be one of the core measures for the improvement of the sector. It was found that the land plots are gradually becoming smaller from generation to generation and therefore the majority of the farmers have one acres or less. Thus, it is advisable to improve organic methods that more appropriate and effective to small land plots.

Positive effect of perceived relative price implies that the vital role of the media could play in promoting safe products. In this regard, farmers will be greatly benefitted by well-designed awareness raising programs. It will further helpful in giving market information. Furthermore, since almost every farmer is literate and is familiar with simple technical devices like mobile phones, market information can be directly sent to the farmers through apps. Moreover, it was revealed that "economic centers" are incapable in controlling intermediation and minimizing farmer exploitation. Majority of the elder farmers stated that door to door collectors gave very satisfied service to small holders while they helped greatly to improve the harmony as well. Thus, it suggestive in establishing farmer associations or corporative s as self-help groups.

It was clearly shown that the attitude changing is invariable in promoting organic methods. Farmers should make aware of their responsibility of producing to the country and care for a clean environment. In this regard, a 
proper and follow-up awareness programs as well as tannings will be very useful. Generally entrepreneurs are risk bears and like to bear higher input costs and even losses in the short run for having greater market opportunity in the future. However, farmers revealed that the market demand for safe products are still not sufficient and producers are not in position to have certification for their products. Therefore, a strong but flexible certification system to introduce genuine organic products are essential in attracting consumers.

\section{References}

Axel Mie, Helle Raun Andersen, Stefan Gunnarsson, Johannes Kahl, Emmanuelle Kesse-Guyot, Ewa Rembiałkowska, Gianluca Quaglio, and Philippe Grandjean, (2017). Human health implications of organic food and organic agriculture: a comprehensive review, Environ Health.; 16: 111.

Batie, S., \& Taylor, D. (1989). Widespread adoption of non-conventional agriculture: Profitability and impacts. American Journal of Alternative Agriculture, 4(3-4), 128-134. doi:10.1017/S0889189300002952

Burton, M., Rigby, D., Young, T. (1999). Analysis of the determinants of adoption of organic horticultural techniques in the UK. J. Agric. Econ., 50 (1): 47-63

Bradbury KE, Balkwill A, Spencer EA, Roddam AW, Reeves GK, Green J, Key TJ, Beral V, Pirie K. (2014). The million women study $\mathrm{C}$ : organic food consumption and the incidence of cancer in a large prospective study of women in the United Kingdom. Br J Cancer. 110 (9):2321-2326.

Chen, Y. S., Zhao, J. J. (2009). An empirical analysis of factors affecting organic vegetable farm production Case Study of Beijing. J. Chin. Rural Econ., 7, 20-30.

Dai Yunyun, Wang Kai. (2008). Study on producing willingness and affecting factors of pear farmers to pollution-free duck pear" empirical analysis of pear farmers in Botou city of Hebei province. Journal of Huazhong Agricultural University (Social Sciences Edition), 6, p47-51

Deng, Mingjun; Xiang, Guocheng, Yao, Shuntian (2018). The Effectiveness of the Multilateral Coalition to Develop a Green Agricultural Products Market in China Based on a TU Cooperative Game Analysis, Sustainability, 10, 1476; doi:10.3390/su10051476

García AM. Pesticide exposure and women's health. Am J Ind Med (2003) 44:584-94.10.1002/ajim.10256

Dharmasena, P.B, Gunasena, Nimal and Jayaweera, Upul. (2017). Sustainable Management Practices for Agricultural Lands in the Central Highlands of Sri Lanka, Part 5 - Upcountry Rain-fed Vegetable Farming System

Gupta S. (2017) Food safety and organic farming. MOJ Food Process Technol.;4(3):81-83. DOI: 10.15406/mojfpt.2017.04.00092

Hansen B, Alroe HF, Kristensen ES, et al. (2002). Assessment of food safety in organic farming. DARCOF 52.

Läpple, D., van Rensburg, T. (2011). Adoption of organic farming: Are there differences between early and late adoption? Ecol. Econ., 70(7), 1406-1414.

Lv Meiye, Wang Kai. (2004). The farmer's willingness to produce "green products" in mountainous areas. Empirical analysis of tea production in Wannan mountainous areas of Anhui province. Journal of Agro technical Economics, 5, p33-37

May, Daniel E. and Paratori, Silvana. (2012). Understanding farmers' willingness to produce healthy and safe products, International Conference RAGUSA SHWA 2012, September 3-6, Ragusa - Italy

McCluskey, J.J. (2000). “A game theoretic approach to organic foods: an analysis of asymmetric information and policy”, Agricultural and Resource Economics 29(1): 1-9.

Mnif W, Hassine AIH, Bouaziz A, Bartegi A, Thomas O, Roig B. (2011) Effect of endocrine disruptor pesticides: a review. Int J Environ Res Public Health 8:2265-2203.10.3390/ijerph8062265

Ranaweera, Sarath. (2016). Organic Agriculture in Sri Lanka and its Potential, Workshop on 'Cultivation and Processing of Organic Agro Crops for Export', Colombo

Wang, Q. (2012). Will farmers adopt organic farming techniques willingly? - Based in Beijing and Shandong Province. J. Chin. Rural Econ., 2012 (2), 99-103.

Willer, Helga and Julia Lernoud, (eds). (2017). The World of Organic Agriculture. Statistics and Emerging Trends 2017 (2018). Bonn: FIBL-IFOAM. 
World Health Organization (WHO), (1990).Public Health Impact of Pesticides Used in Agriculture. England: World Health Organization

Xie, Yumei ; Zhao, Hailei; Pawlak, Karolina and Gao, Yun (2015). The development of organic agriculture in china and the factors affecting organic farming 2(36), 353-361

Ying ,Xiong and Min, Luo (2011). Research on Farmers' Production Willingness of Safe Agricultural Products and Its Influence Factors: An Empirical Analysis in China, Energy Procedia 5 53-58

Zhang, L.G. (2008) Analysis on the moral hazard in farmers' organic food production. Econ. Probl., 12, 93-96.

Zhu, D.; Zhang, X.L.; Niu, L.Y. (2014). Vegetable farmers' willingness to adopt bio pesticides. China Popul. Resour. Environ., 24, 64-70 